\title{
Análise do layout e as estratégias de merchandising em uma farmácia situada em São João dos Patos Maranhão
}

\author{
Analysis of the layout and strategies of merchandising in a pharmacy located in São João \\ dos Patos Maranhão
}
Análisis del diseño y las estrategias de comercialización en una farmacia localizada en San Juan de los Patos Maranhão

\begin{abstract}
Kairo dos Santos ${ }^{1 *}$, Francisca Milena Sousa Gomes ${ }^{1}$, Jeorgio Leão Araújo ${ }^{1}$, Deyna Francélia Andrade Próspero', Maria Helena Rodrigues Mesquita Britto'.
\end{abstract}

\section{RESUMO}

Objetivo: Este trabalho objetivou analisar o Layout e as estratégias de merchandising em uma farmácia comercial. Métodos: Foi usado um questionário composto por 22 questionamentos sobre técnicas empregadas em estrutura, Layout e Merchandising na farmácia e aplicado ao estabelecimento para análise. Resultados: Os dados da pesquisa mostraram que o estabelecimento apresenta entrada com acesso para deficientes, portas amplas, apresentam em sua faixada cores vermelho e azul com fundo branco; observouse também que a farmácia o apresenta uma iluminação deficiente e o mobiliário não é condizente com seu público, além disso, o espaço de circulação é reduzido não dispondo de estacionamento próprio. Com relação ao layout, as gôndolas apresentam pontas arredondadas e totalmente preenchidas seguindo uma lógica de organização dos seus produtos; os produtos expostos nas gôndolas estão ao alcance das mãos dos consumidores, mas não apresentam preço visível. A farmácia não apresenta $80 \%$ de autos serviço. A localização da balança está acessível dentro do estabelecimento. O balcão encontra-se localizado no fundo do estabelecimento é curto, a farmácia apresenta o gerenciamento por categorias. Ao analisarmos a situação da farmácia quanto ao uso do merchandising, o ambiente interno está indevidamente sinalizado. Não foram observados produtos promocionais na loja, os produtos da farmácia estão adequadamente limpos e organizados; os medicamentos estão dispostos nas estantes corretamente; o caixa se encontra atrás do balcão. A farmácia apresenta alguns documentos de regulação visível para os clientes. Conclusão: Usar técnicas de layout e merchandising corretamente influencia diretamente nas vendas da empresa promovendo impacto nas vendas aumentando a lucratividade da loja.

Palavras-chave: Mercado farmacêutico, Layout, Merchandising, Empreendedorismo, Farmácia.

\begin{abstract}
Objective: This work aimed at Layout and merchandising strategies in a commercial pharmacy. Methods: Threaded and Merchandising in research and methods for analysis. Results: The survey data were edited with access for the disabled, wide doors, in red and white with white background; also showed up with bad lighting label and the exterior is not consistent with its audience, moreover, the circulation space is not yet available. Regarding the layout, such as gondolas the tips fully and completely filled by a logic of organization of their products; The products on the shelves are within the reach of consumers, but they are not visible prices. The pharmacy does not have $80 \%$ of automatic service. The balance location is available within the property. The counter is located at the bottom of the property is short, a pharmacy presents management by
\end{abstract}

\footnotetext{
${ }^{1}$ Centro Universitário Santo Agostinho - UNIFSA. *E-mail: kairorony15@hotmail.com
} 
categories. When analyzing a business situation for merchandising, the internal environment is unduly signaled. Food products are not observed, and the products of the pharmacy are assembled and organized; the medicines are working on the shelves properly; the box is behind the counter. The farm has some control documents visible to customers. Conclusion: Use layout and merchandising techniques as the influence of store profitability.

Keywords: Pharmaceutical market, Layout, Merchandising, Entrepreneurship, Drugstore.

\section{RESUMEN}

Objetivo: Este trabajo tuvo como objetivo el Layout y las estrategias de merchandising en una farmacia comercial. Métodos: Threaded and Merchandising en investigación y métodos para análisis. Resultados: Los datos de la encuesta fueron editados con acceso para los discapacitados, las puertas amplias, en rojo y blanco con fondo blanco; también se mostró con el rótulo de iluminación deficiente y el exterior no es acorde con su público, además, el espacio de circulación todavía no está disponible. Con respecto al layout, como góndolas las puntas enteras y totalmente llenadas por una lógica de organización de sus productos; Los productos expuestos en las góndolas están al alcance de las manos de los consumidores, pero no son precios visibles. La farmacia no presenta un $80 \%$ de servicio automático. La ubicación de la balanza está disponible dentro del establecimiento. El mostrador se encuentra ubicado en el fondo del establecimiento es corto, una farmacia presenta la gestión por categorías. Al analizar una situación de negocio para el merchandising, el ambiente interno está indebidamente señalado. Los productos alimenticios no se observan, y los productos de la farmacia están reunidos y organizados; los medicamentos están funcionando en las estanterías correctamente; el cuadro se encuentra detrás del mostrador. La granja tiene algunos documentos de control visibles para los clientes. Conclusión: Utilice las técnicas de diseño y merchandising como la influencia de la rentabilidad de la tienda.

Palabras clave: Mercado farmacéutico, Diseño, Merchandising, La iniciativa empresarial, Farmacia.

\section{INTRODUÇÃO}

O comércio ou varejo é descrito por Silva (2010), como sendo uma das atividades mais primitivas que a sociedade reconhece, sendo formada por um ciclo de consumo entre produtores, distribuidores e consumidores. O que diferencia esses produtores são o formato, estrutura e intensidade de seus negócios. Nesse contexto, a farmácia é a principal fornecedora para o consumo de medicamentos. De acordo com o Ministério da Fazenda, as farmácias e drogarias são responsáveis por cerca de quase $80 \%$ do fornecimento direto de medicamentos à população (BRASIL, 2004).

No Brasil o comércio de medicamentos é representado principalmente por grandes e pequenas drogarias independentes e por redes de farmácias. Segundo a Abrafarma (2012), o Brasil possui em torno de 66 mil drogarias e farmácias, responsáveis pela venda de medicamentos, produtos de higiene pessoal, perfumaria e cosméticos.

O varejo apresenta um caráter único por apresentar contato direto com o consumidor final. Engel, et al. (2000) sugerem que, mesmo que um produto seja bem apreciado ele não tem valor se os varejistas não o disponibilizem de forma a criar consumidores satisfeitos. Contudo, o ramo varejista proporciona números significativos. Segundo o Instituto para Desenvolvimento do Varejo - ICV (2015), "o varejo é o setor privado que possui o maior número de empregados formais e suas vendas apresentam crescimento médio anual de 7,2\% entre 2004 e 2014, atingindo uma participação de $26 \%$ do produto interno bruto".

No contexto de mercado, o varejo forma uma das áreas mais competitivas, criativas e fragmentadas da economia, e vem seguindo um intervalo de grandes alterações e desenvolvimento, contestando às mudanças do ambiente tecnológico, econômico e social em que está inserida. Essa aparente competitividade dentro do mercado varejista, expõe a importância eminente das empresas mostrarem uma gestão bem objetiva no 
intuito de liderar e administrar de forma exata as suas atividades. Administrar é praticar um conjunto de ações sistêmicas em determinados período e de tal forma que todas sejam otimizadas (LOOF, 2003).

Dentre as dentre as principais peculiaridades do mercado de farmácias no Brasil, destacam-se o crescimento rápido, o varejo de farmácias vem apresentando números significativos nos últimos anos, oferecendo faturamento de vendas de aproximadamente $R \$ 43$ bilhões em 2011 frente aos $R \$ 17$ bilhões em 2004; O varejo como mercado fragmentado apresenta cerca de $35 \%$ do total de faturamento nas mãos de pouca mais de 10 empresas (ABRAFARMA, 2012).

Compreendendo essa concepção que o mercado está cada vez mais desenvolvido e globalizado, onde o cliente está cada vez mais exigente e seus concorrentes ainda mais competitivos, gestores necessitam implantar avaliações do layout utilizado nas farmácias, bem como as estratégias de merchandising da empresa. Estas análises contribuem para que haja uma transformação entre as empresas auxiliando para o seu desenvolvimento (TREIN, 2001).

Entretanto, a preferência do layout pode favorecer a intercomunicação das técnicas de produtos e privilégios competitivas. O layout é um dos aspectos mais perceptíveis de um efeito proveitoso, porque especifica sua forma e imagem, além de organizar o modo conforme a qual os recursos modificados como materiais, conhecimentos e fregueses procedem através da realização (LOFF, 2003).

O princípio de layout consiste em planejar as repartições da loja (divisão por tipo de produto, caixas, provadores) e de maneira completa, um ideal uso do local atual para expor e destacar os produtos (SILVA e PINHEIRO, 2010).

O merchandising envolve a noção e a ciência de apresentar os produtos de maneira visualmente mais atrativa. É a maneira com que os varejistas interagem com os clientes por meio de propostas visuais ou apresentações de um produto. Para Craveiro (2010), o estimulo deve incitar mais de um sentido humano para que o cliente chegue a realizar a compra. "À medida que mais incentivos diferentes envolvem uma compra, cria-se uma prática de compra que faz com que o cliente se envolva mais com aquele local e, portanto, crie lealdade e compre mais" (CRAVEIRO; 2010).

Blessa (2014), afirma que a diversidade de produtos oferecidos nas drogarias oferece maior comodidade ao consumidor além de diversificar seus fornecedores diminuindo a dinâmica das indústrias farmacêuticas, que em relação à indústria de alimentos apresenta-se muito mais fechada. Outro ponto que tem que ser levado em consideração é o melhoramento do layout das lojas. O nosso objeto de estudo, a farmácia, vem atravessando um forte processo de reestruturação de layout a fim de aumentar as expectativas do cliente ao entrar em contato com as prateleiras e interior de loja. Então, pretende-se avaliar questões relacionadas às estratégias de merchandising e layout, se for necessário, desta farmácia e que nos ajudará a traçar um perfil da atual farmácia no Maranhão.

A escolha do tema aqui proposto deve-se, sobretudo, ao interesse no que concerne às temáticas relacionadas à importância do varejo farmacêutico. Apesar da importância cada vez mais significativa do mercado de varejo farmacêutico no Brasil, estudos acadêmicos nessa área não são tão frequentes como de outros mercados já fortalecidos há muito tempo no país. Dessa forma, pesquisas de caracterização do varejo e merchandising são extremamente importantes para sua melhor compreensão, contribuindo, assim, para seu desenvolvimento continuo (TELES et al, 2010).

Esse trabalho engloba um estudo geral sobre varejo, merchandising e layout, de forma a descrever suas principais características, breve histórico no Brasil e possíveis soluções para melhora do serviço na farmácia que servirá de base para análise. O objetivo do presente trabalho foi analisar o layout e as estratégias de merchandising em uma farmácia situada em São João dos Patos - MA. Assim como, verificar a organização atual do estabelecimento em relação a sua estrutura, analisar a disposição atual da farmácia quanto ao layout e averiguar a ordenamento atual da farmácia quanto às estratégias de merchandising e varejo. Portanto, os possíveis resultados terão relevância na ampliação dos conhecimentos acerca desse mercado em ascensão e poderá servir como objeto de estudo para gestores na área de farmácia e conhecimentos afins. 


\section{METODOLOGIA}

\section{Caracterização do estudo}

Trata-se de um estudo de caráter exploratório, com abordagem qualitativa e delineamento transversal baseado em fonte de dados documentais obtidos através das Diretrizes para estruturação das farmácias de acordo com o Conselho Federal de Farmácia do Brasil, cujo instrumento para coleta de dados utilizados foi um questionário baseando se no layout e estratégias de merchandising no ambiente da farmácia comunitário adaptado a partir de orientações estabelecidas pela Associação Brasileira de Farmácias e Drogarias ABRAFARMA.

\section{Amostras, critérios de inclusão e exclusão}

A pesquisa foi realizada em uma farmácia comercial localizada na cidade de São João dos Patos - MA. Durante a coleta de dados foram analisados vários itens relacionados à estrutura, o layout e estratégias de merchandising no ambiente da farmácia comunitária, a partir do preenchimento de um questionário estruturado contendo 22 questões (anexo) (ABRAFARMA). Foram incluídos na pesquisa uma farmácia comunitária, bem como as estantes, balcões e a disposição dos produtos e medicamentos nela dispostos. Foram excluídas da pesquisa as demais farmácias da cidade São João dos Patos - MA. Todas as análises e fotos realizadas na farmácia comercial durante a pesquisa e escrita deste trabalho tiveram consentimento do responsável pelo estabelecimento.

\section{Riscos e benefícios}

O trabalho foi desenvolvido através de levantamento de dados e ferramentas visuais (fotos), os riscos do trabalho são remotos e estão relacionados à divulgação de informações que não condiz com a realidade local, no entanto, a pesquisa será mantida em sigilo quanto à identidade da farmácia, podendo também haver implicações relacionadas com a manipulação das ferramentas de informática. Quanto aos possíveis benefícios do trabalho está na análise do layout e as estratégias de merchandising em uma farmácia comercial.

\section{RESULTADOS E DISCUSSÃO}

Este trabalho pretende alcançar as relações sociais para a conquista de hábitos e condutas de consumo, a fim de serem aplicados de forma estratégica na preparação e administração do layout da loja, ou seja, seu arranjo físico, e na forma como os produtos devem ser expostos para o cliente dentro do ponto-de-venda, através do visual merchandising, para que se torne um diferencial competitivo (MEDINA, 2015).

No quadro 1 estão listados questionamentos com relação a estrutura física da farmácia comercial em estudo. Os dados da pesquisa mostraram que o estabelecimento apresenta em sua entrada acesso para pessoas deficientes. A farmácia possui portas amplas que possibilitem uma melhor visualização de todo o estabelecimento e apresenta em sua faixada cores com capacidade de estimulação sensorial e carga simbólica (como, por exemplo, vermelho, azul, amarelo ou laranja) nas cores vermelho e azul com fundo branco (Figura 1).

A acessibilidade a pessoas com deficiência é um direito garantido pela Lei Federal № 10.098, de 19 de dezembro de 2000, que estabelece normas gerais e critérios básicos para a promoção de acessibilidade das pessoas portadoras de deficiência ou com mobilidade reduzida. Em seu Art. 11 a lei assegura que a construção, ampliação ou reforma de edifícios públicos ou privados destinados ao uso coletivo deverão ser executadas de modo que sejam ou se tornem acessíveis às pessoas portadoras de deficiência ou com mobilidade reduzida (BRASIL, 2000). Assim, a farmácia deve proporcionar essa acessibilidade a todos os tipos de pessoas, disponibilizando rampas e/ou automatização de portas, figura 1 (BOBO, 2005). 
Quadro 1 - Disposição atual da farmácia comercial quanto a sua estrutura.

\begin{tabular}{|l|c|c|}
\hline \multicolumn{1}{|c|}{ Aspectos observados } & Sim & Não \\
\hline 1. Existe na entrada da drogaria acesso para pessoas deficientes? & $\mathbf{X}$ & \\
\hline 2. Existe iluminação eficiente no ambiente interno? & & $\mathbf{X}$ \\
\hline 3. O mobiliário está adequado ao público que frequenta o estabelecimento? & & $\mathbf{X}$ \\
\hline $\begin{array}{l}\text { 4. A farmácia possui portas amplas que possibilitem uma melhor visualização de } \\
\text { toda a farmácia? }\end{array}$ & $\mathbf{X}$ & \\
\hline 5. A drogaria possui estacionamento para automóvel? & $\mathbf{X}$ & \\
\hline $\begin{array}{l}\text { 6. A farmácia apresenta cores com capacidade de estimulação sensorial e carga } \\
\text { simbólica (como, por exemplo, vermelho, azul, amarelo ou laranja)? }\end{array}$ & $\mathbf{X}$ & \\
\hline
\end{tabular}

Fonte: Dados da pesquisa, 2018.

O estabelecimento deve dispor de um espaço que permita a circulação dos clientes, pois é através dela que os consumidores têm liberdade de visualizar bem todos os produtos oferecidos. A porta de entrada da farmácia é ampla (Figura 1), onde facilita a entrada e a visualização interna das pessoas que estão do lado de fora despertando o interesse de compras (BLESSA, 2014).

Figura 1- Fachada frontal da farmácia comercial.

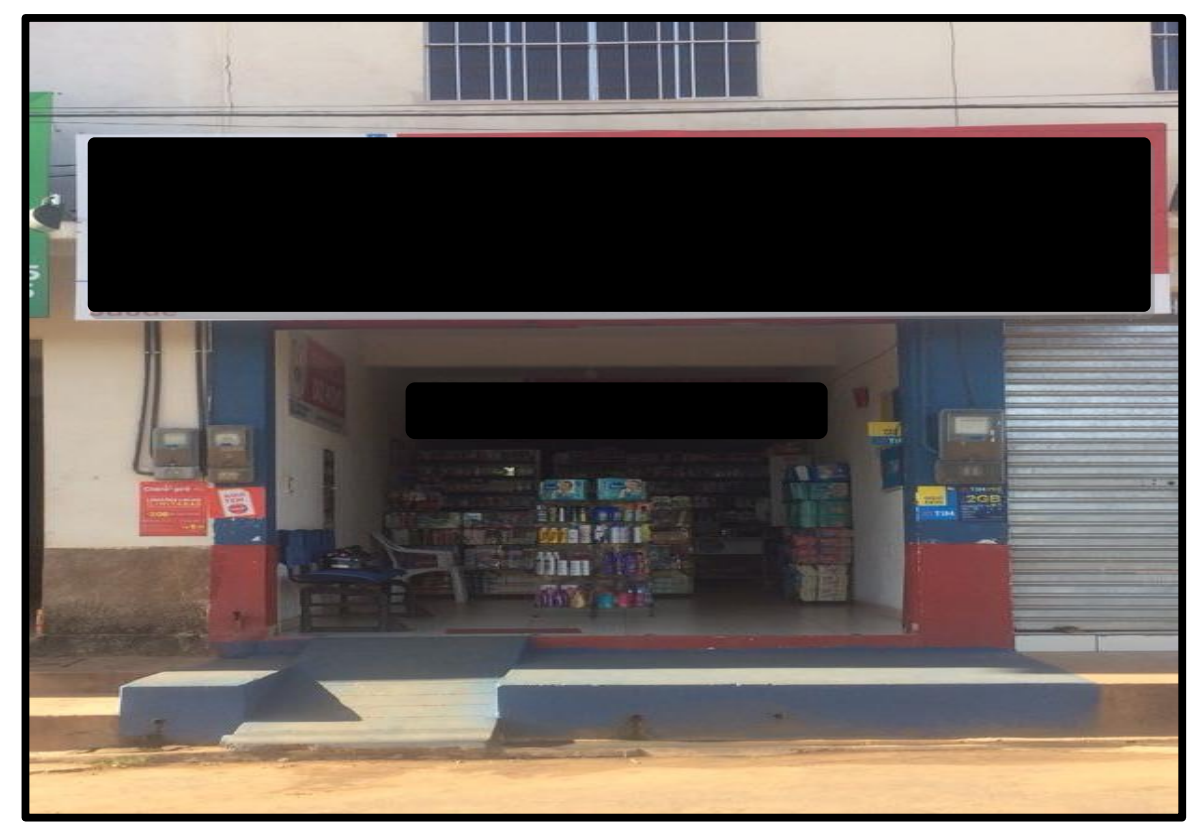

Fonte: Dados da pesquisa, 2018.

As cores usadas na faixada externa da farmácia são azul e vermelho com fundo branco (Figura 1). Segundo Carrasco (2005), as cores quentes como o vermelho, amarelo e laranja induzem compras compulsivas, enquanto as cores frias como o azul, verde e violeta induzem as compras refletidas. A cor predominante dentro da farmácia foi o branco. Essa foi uma conduta feliz, pois as cores mais apropriadas para o interior da loja são cores claras como o branco, o creme e o pastel, uma vez que elas ampliam o espaço e são menos cansativas. A importância de usar a cor azul é que ela transmite autoconfiança, segundo alguns especialistas o estabelecimento com um fundo azulado o cliente prestará mais atenção conseguindose uma maior fidelização (CARRASCO, 2005). 
Observou-se que a farmácia não apresenta uma iluminação eficiente no ambiente interno, apresentando áreas de penumbra, as quais denotam uma sensação de desconforto para os clientes. Essa situação compromete o bom atendimento ao cliente uma vez que a farmácia é um estabelecimento de saúde, e sendo assim deve estar sempre limpa e sem odores e disponha de uma boa iluminação, contribuindo para o bem estar do cliente e facilitando a visualização dos produtos (RAMOS, 2014). Ainda segundo Ramos (2014) o cliente só entra em loja mal ilumina e de aparência precária quando é estritamente necessário, e as compras são feitas rapidamente, sem que haja interesse de ver o restante dos produtos oferecidos. Já um ambiente bem iluminado faz com que os consumidores sintam uma vontade irresistível de entrar apenas para conhecer novos produtos ou comprar muito além do planejado.

A organização de um estabelecimento comercial é um dos requisitos que pode fazer com que a farmácia se diferencie no mercado da região. A farmácia pesquisada não apresenta distribuição do mobiliário condizente com seu público, o espaço de circulação entre os consumidores não é suficiente para que as vendas por impulso possam ser estimuladas (BLESSA, 2014).

Segundo Costa (2014), a escolha do mobiliário correto é tão importante quanto sua posição de maneira estratégica, para que se garanta um bom espaço de circulação entre os consumidores e para que as vendas por impulso sejam estimuladas. Colocar o balcão de medicamentos e o caixa sempre em sentidos opostos para que os consumidores possam circular por toda a loja antes do pagamento, conhecendo ou lembrandose de produtos que não estão na lista de compras é sempre uma boa estratégia. É importante estar sempre atento ao fluxo da loja. É preciso observar a atitude das pessoas quando entram na loja e o caminho que preferem ou não dentro de seu roteiro de compras.

Com relação à oferta de estacionamento para os clientes, foi observado que a farmácia não dispõe de um espaço na frente do estabelecimento, onde os clientes possam estacionar seus automóveis enquanto realizam suas compras. Segundo a Lei Federal № 10.518/12 há uma autorização de estacionamento gratuito de veículos para clientes de drogaria. O estacionamento é permitido por no máximo 10 minutos, com sinalização de emergência (pisca-alerta) acionada (RAMOS, 2014).

Quanto à análise da disposição do layout da farmácia comercial (Quadro 2), observou-se que as gôndolas apresentam pontas arredondadas com altura condizentes em relação a estatura da população e apresentamse totalmente preenchidas seguindo uma lógica na organização dos seus produtos (Figura 2). Uma das características dos layouts de farmácias é a redução do espaço dedicado ao armazenamento de produtos em gôndolas que se repartem em uma grande área do local de venda (ALMEIDA e MARQUES, 2013).

A distribuição das gôndolas (Figura 3) deve apresentar uma sequência lógica durante o armazenamento de produtos, ou seja, os produtos que tem relação entre si são colocados próximos uns dos outros. Quando isso é feito de forma lógica, os clientes entendem os corredores e ficam mais à vontade, o que influencia as compras por impulso e o cliente acaba gastando mais (MELLO, 2016).

De acordo como o que se pode observar na Figura 3, os produtos expostos nas gôndolas estão ao alcance das mãos dos consumidores, mas não apresentam preço visível. A maioria dos produtos não está com preços afixados e não consta o valor dos produtos nas prateleiras. Segundo Blessa (2014), o preço visível nos produtos expostos torna-se mais cômodo para o comprador, dando liberdade de escolha e facilitando a compra. Isso favorece o autosserviço oferecido pelas farmácias. A farmácia analisada não apresenta $80 \%$ de autosserviço, o que seria o ideal para a loja. Quando os produtos estão bem expostos no autosserviço às vendas crescem em todas as categorias e a farmácia pode alcançar um faturamento de $50 \%$ nas gôndolas e $50 \%$ no balcão.

A localização da balança está em um ponto acessível dentro do estabelecimento (Figura 4-A), permitindo livre acesso para os interessados. O posicionamento adequado da balança dentro da farmácia favorece a atração de clientes influenciando diretamente nas vendas.

Outro quesito analisado foi à localização do balcão de atendimento do empreendimento. Este por sua vez encontra-se localizado no fundo do estabelecimento e não são longos, como mostra a Figura 4-B. O balcão 
representa o espaço mais quente da farmácia, pois é o elemento de maior visibilidade. A maioria das vendas da farmácia e onde ocorre o contato direto com o consumidor é no balcão. Para facilitar a comunicação é importante que o balcão não seja longo, para não dificultar esse contato (CRAVEIRO, 2010).

Quadro 2 - Disposição atual da farmácia comercial quanto o layout.

\begin{tabular}{|ll|c|c|}
\hline \multicolumn{1}{|c|}{ Aspectos observados } & Sim & Não \\
\hline 1. As gôndolas apresentam pontas arredondadas? & $\mathbf{X}$ & \\
\hline 2. A altura das gôndolas está condizente com a estatura da população? & $\mathbf{X}$ & \\
\hline 3. As gôndolas apresentam-se totalmente preenchidas? & $\mathbf{X}$ & \\
\hline 4. Há lógica na organização dos produtos? & $\mathbf{X}$ & \\
\hline 5. Os preços estão afixados em cada produto? & & $\mathbf{X}$ \\
\hline 6. Os preços estão afixados de forma visível na prateleira? & $\mathbf{X}$ \\
\hline 7. A farmácia apresenta no mínimo 80\% da sua área total para o setor \\
de autosserviço?
\end{tabular}

Fonte: Dados da pesquisa, 2018.

Figura 2 - Exposição de produtos em gôndolas na farmácia comercial.

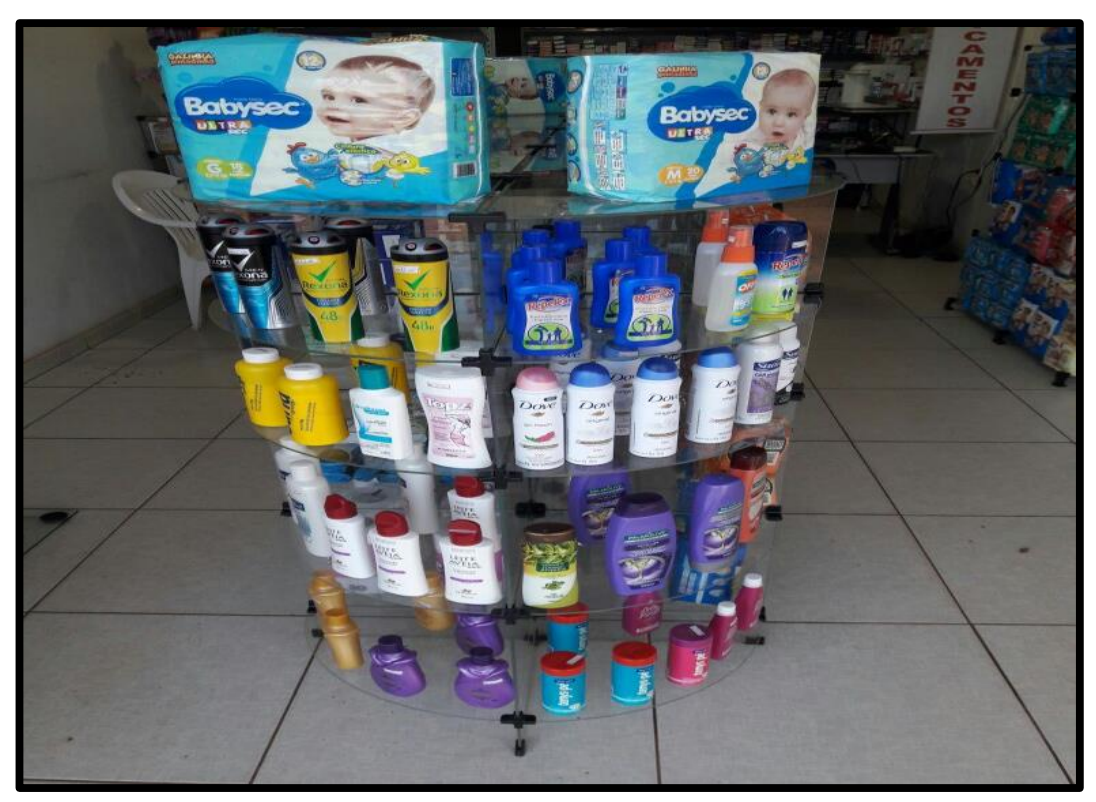

Fonte: Dados da pesquisa, 2018. 
Figura 3 - Organização dos produtos em sequência lógica nas gôndolas da farmácia comercial.
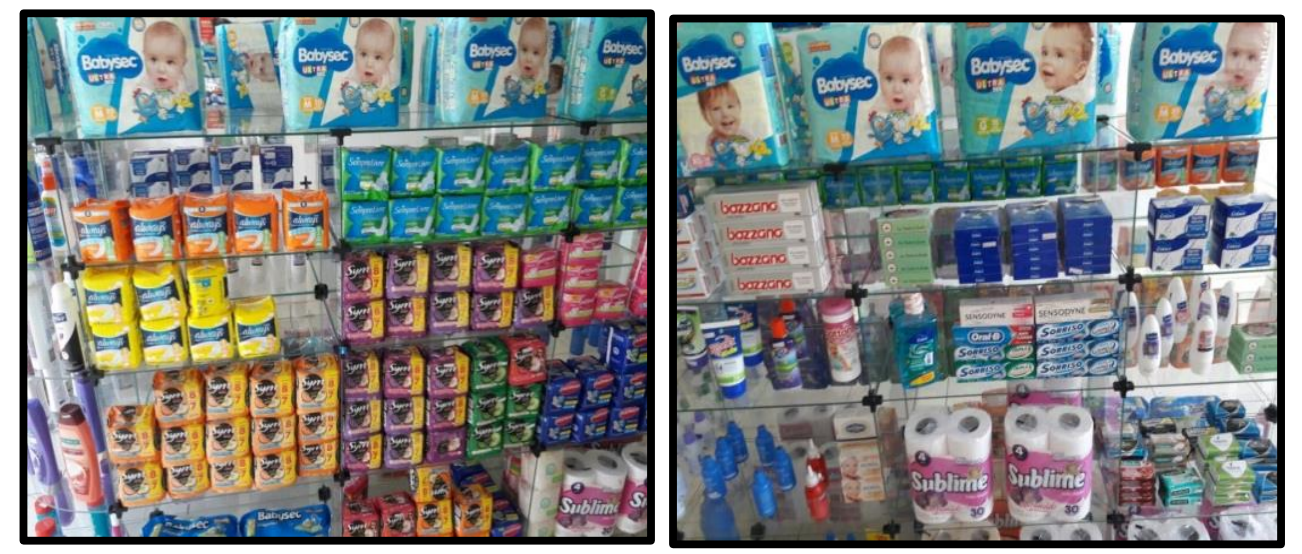

Fonte: Dados da pesquisa, 2018.

Figura 4 - Localização da balança acessível aos clientes (A); e Localização do balcão de atendimento da farmácia comercial $(B)$.

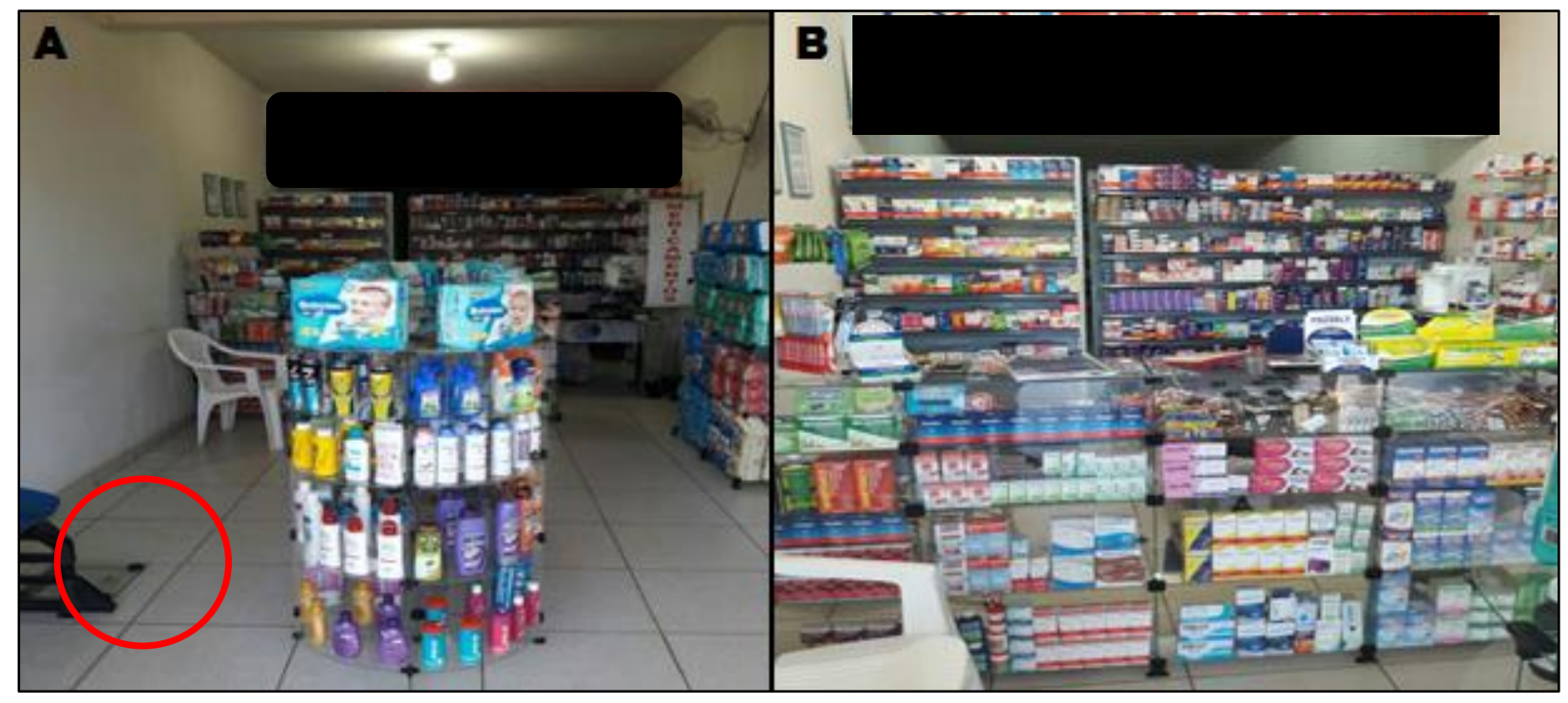

Fonte: Dados da pesquisa, 2018.

Na pesquisa realizada, a farmácia apresenta o gerenciamento por categorias. Segundo Ortiz (2013), esse gerenciamento é um processo de parceria entre varejista e fornecedor que consiste em definir categorias de produtos conforme a necessidade que atendam e gerenciá-las como se fossem unidades estratégicas de negócios. O objetivo desse gerenciamento por categorias é somar as vendas e a os lucros por meio de esforços para agregar maior valor ao consumidor final (ORTIZ, 2013).

Para Craveiro (2010), elaborar um bom espaço de exibição de produtos não é uma tarefa difícil, mas requer raciocínio lógico e planejamento. É na área de exposição dos produtos que se aplicam as técnicas vitais do merchandising.

Ao analisarmos a situação da farmácia quanto ao uso do merchandising, observou-se que o ambiente interno não está devidamente sinalizado. A sinalização das categorias e dos produtos deve estar no campo de visão dos clientes, facilitando a identificação. Essas placas sinalizadoras são de grande importância dentro 
do estabelecimento, porque facilita o direcionamento do cliente para o setor desejado mais rápido, evitando que o consumidor perca tempo procurando o produto desejado, mesmo que o estabelecimento comercial seja de pequeno porte. Por exemplo, em uma categoria complexa de produtos como fraldas descartáveis, podemse sinalizar dois fatores de decisão do consumidor: tamanho (RN, PP, P, M, G, XG e XXG) e adulto/ infantil (CASAS e GARCIA, 2013).

Quadro 3 - Disposição atual da farmácia comercial quanto às estratégias de merchandising.

\begin{tabular}{|l|c|c|}
\hline \multicolumn{1}{|c|}{ Aspectos observados } & Sim & Não \\
\hline 1. O ambiente interno está devidamente sinalizado? & & $\mathbf{X}$ \\
\hline 2. Há produtos em promoção de maneira que estimule a compra deste? & $\mathbf{X}$ \\
\hline 3. Produtos estão sempre limpos? & $\mathbf{X}$ & \\
\hline 4. Os produtos nas parteleiras tem o seu "facing" explorado adequadamente? & $\mathbf{X}$ & \\
\hline 5. O check-out está localizado à frente da farmácia? & & $\mathbf{X}$ \\
\hline 6. Os documentos sanitários estão em local de fácil visualização pelo consumidor? & $\mathbf{X}$ & \\
\hline
\end{tabular}

Fonte: Dados da pesquisa, 2018.

Não foram observados produtos com promoção na loja. Para Saab (2001), promoção é uma estratégia de comunicação, que tem como objetivo divulgar os produtos e serviços oferecidos. A promoção é composta pro cinco elementos: propaganda e venda pessoal, promoção de vendas, relação pública e marketing direto (KOTLER, ARMSTRONG, 2003).

Os produtos da farmácia estão adequadamente limpos e organizados. Essa prática favorece diretamente na lucratividade da empresa influenciando nas vendas.

Analisamos também se o facing, espaço frontal ocupado pelo produto na prateleira, dos medicamentos dispostos nas estantes estavam dispostos corretamente e observou-se que eles estavam dispostos de frente na primeira fila do expositor como pode ser observado na figura 6. Essa técnica de exploração de facing dos produtos atrai os clientes, porque é um tipo de comunicação silenciosa, ou seja, o produto chama atenção do consumidor, despertando o interesse de compra. A parte principal do produto deve ficar o mais visível possível para o cliente (KOTLER e ARMSTRONG, 2003).

Figura 5 - Apresentação do facing dos medicamentos dispostos nas estantes da farmácia comercial.

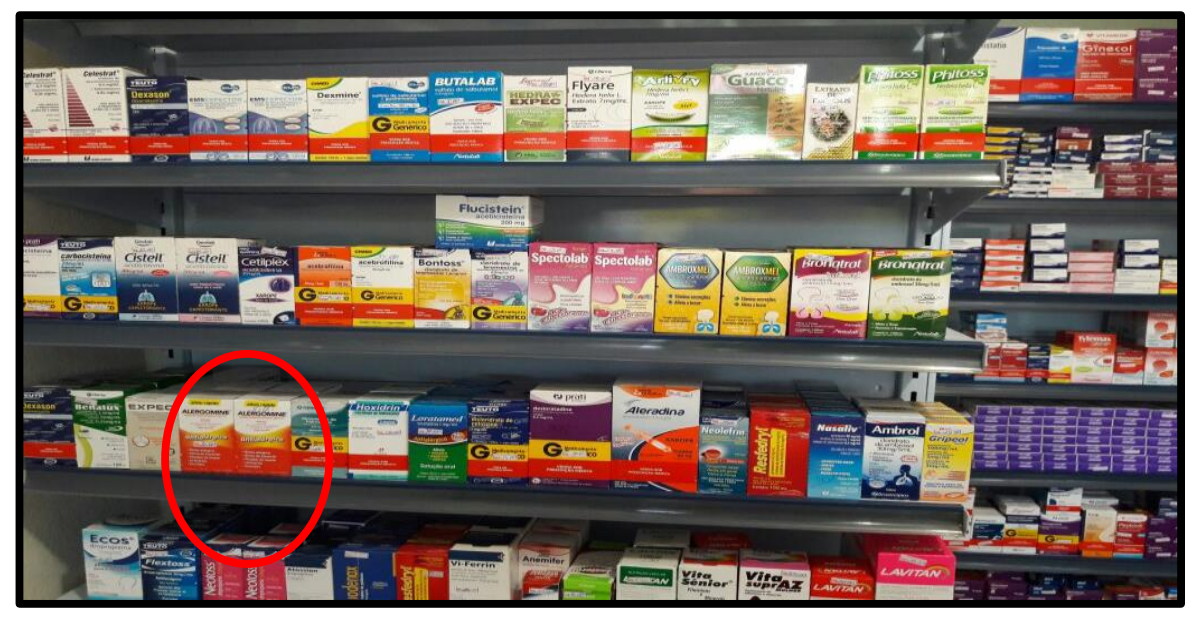

Fonte: Dados da pesquisa, 2018. 
Figura 6 - Localização do check-out (caixa) da farmácia comercial.

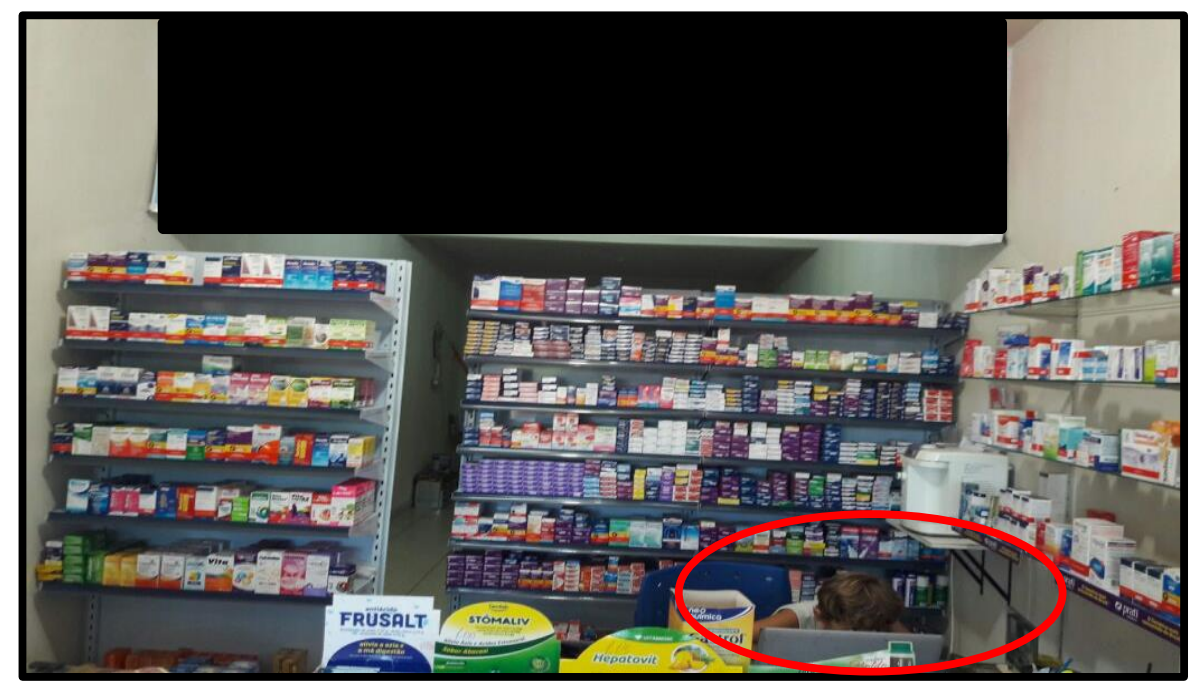

Fonte: Dados da pesquisa, 2018.

Quando o quesito observado foi a localização do check-out (caixa), a farmácia não apresenta uma boa localização para o caixa, como pode ser observado na Figura 7, ele se encontra atrás do balcão. $O$ mais apropriado seria estar posicionado à frente da loja e contar com gôndolas contendo produtos de baixo valor e em oferta, a fim de facilitar a compra por impulso e facilitar o troco (GERLACH, 2013).

Figura 7 - Documentos que comprovam o funcionamento regular da farmácia comercial.

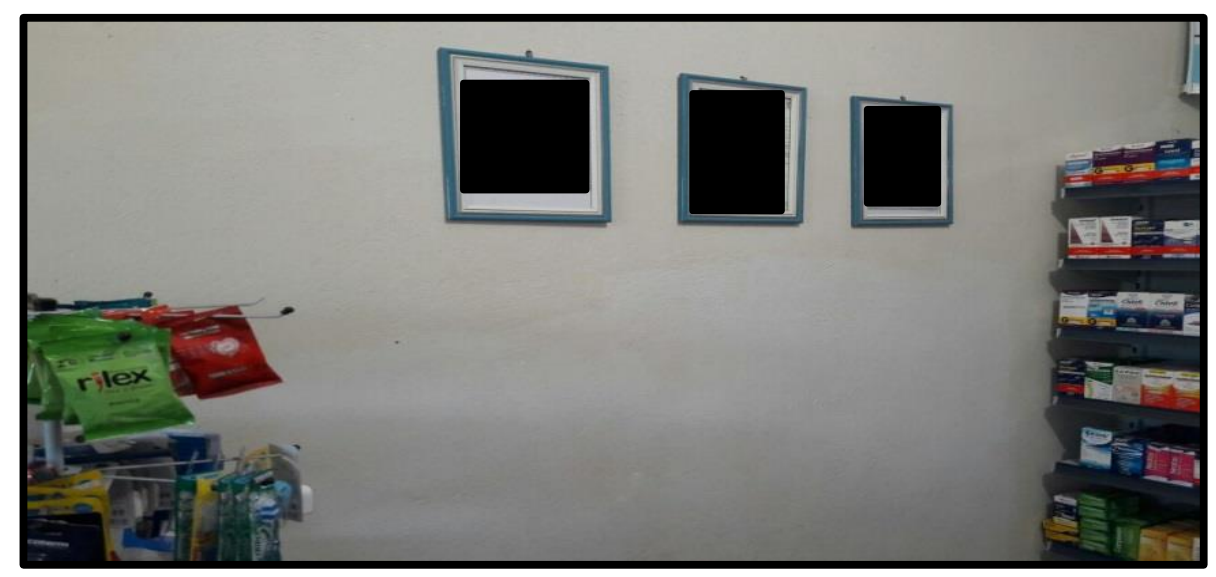

Fonte: Dados da pesquisa, 2018.

Segundo Gonzalez et al. (2012), alguns documentos devem ficar expostos em um quadro de avisos, dentro da farmácia, como por exemplo: Alvará de funcionamento da Prefeitura; Certificado de Regularidade (CRF); Alvará Sanitário da Secretaria da Saúde, estadual ou municipal; Autorização de Funcionamento (ANVISA), Autorização Especial de Funcionamento (Controlados - Farmácias e Drogarias), e cadastramento para farmácias magistrais que trabalhem com medicamentos sujeitos a controle da Portaria 344, de 12/5/1998. A farmácia estudada apresenta alguns documentos que comprovam seu funcionamento regularizado pelos órgãos responsáveis expostos de forma visível para os clientes e demais interessados, isso gera autoconfiança do consumidor. 


\section{CONCLUSÃO}

O presente trabalho mostrou uma avaliação do layout e estratégias de marketing de uma farmácia de comunidade de pequeno porte localizada na cidade de São João dos Patos no estado do Maranhão. A pesquisa na farmácia mostrou que o estabelecimento apresenta algumas falhas nos quesitos estruturais como deficiência de iluminação, ausência de estacionamento; no quesito layout a loja peca por apresentar os produtos sem os preços visíveis fixados dificultando os autos serviços dos clientes, o balcão é curto e encontra-se no fundo do estabelecimento facilitando o contato consumidor e atendente. Já no quesito marketing, o estabelecimento não apresentou produtos em promoção nem sinalização de orientação aos clientes na hora de escolher o que comprar. O balcão de check-out (caixa) da farmácia encontra-se erroneamente localizado no fundo da farmácia, perdendo a oportunidade de faturar ainda mais. Se o balcão estivesse localizado na saída da loja o empreendedor aproveitaria para expor produtos de compra rápida próximo para induzir o cliente a comprar compulsivamente na hora de pagar a conta. Usar técnicas de layout e merchandising corretamente influencia diretamente nas vendas da empresa. Estas técnicas promovem um impacto nas vendas aumentando a lucratividade da loja.

\section{REFERÊNCIAS}

11. ALMEIDA JSC, MARQUES NB. Merchandising no ponto-de-venda: uma ferramenta Estratégica, Convibra Administração. Congresso Virtual Brasileiro de Administração, Portugal, 2013.

12. ANFARMAG. Aspectos das Farmácias em Portugal e na União Européia. Revista da Farmácia Magistral, São Paulo, out. 2009.

13. ANZANELLO MJ, LEMOS FO, ECHEVESTE ME. Aprimorando Produtos Orientados ao Consumidor Utilizando Desdobramento da Função Qualidade (QFD) e Previsão de Demanda - Revista: Produto \& Produção, 2009 , vol. 10, n. 2, p. $01-27$.

14. ARAÚJO KBF. Análise de alguns pontos de venda em relação a conceitos de merchandising, UNIGRAN Dourados - MS, 2015 vol. 04, n. 09, p. 42-59, jan-jun.

15. BARETA GMSA. Atenção farmacêutica nas farmácias comunitárias do município de Campina Grande do Sul, Visão Acadêmica, Curitiba, 2003, v. 4, n. 2, p. 105-112, Jul.- Dez..

16. BASTOS CRG, CAETANO R. As percepções dos farmacêuticos sobre seu trabalho nas farmácias comunitárias em uma região do estado do Rio de Janeiro. Ciência \& Saúde Coletiva, Rio de Janeiro, 2010, p. 3541-3550.

17. BLESSA R. Merchandising no ponto-de-venda. 2014, 4.ed-10.reimpr. São Paulo: Atlas.

18. BOBO E. Marketing y Merchandising. Correio Farmacêutico, 2005, 185, pp.22-28.

19. BRASIL. LEI No 10.098, DE 19 DE DEZEMBRO DE 2000. Portal do MEC. Disponível em: http://portal.mec.gov.br/arquivos/pdf/lei10098.pdf, acesso em 12/05/2018, as 20:00 hs.

20. CARRASCO N. Escaparatismo em La farmácia. Correio Farmacêutico, 2005, 193, PP.16-26.

21. CARVALHO MSDS. A gestão em farmácia comunitária: metodologias para aperfeiçoar a rentabilidade da farmácia, universidade Lusófona de Humanidades e Tecnologias, Lisboa, 2013.

22. CASAS ALL, GARCIA MT. Estratégias de Marketing para Varejo: Inovações e diferenciações estratégicas que fazem a diferença no marketing de varejo, Novatec, 2013.

23. CHRISTENSEN DB, FARRIS KB. Pharmaceutical care in community pharmacies: practices and research in the US. Ann Pharmacother, 2006, v. 40, n. 7-8, p. 1400-1406.

24. COHN M. Passando a tocha. São Paulo: Makron Books, 1991.

25. CRAVEIRO BDCNB. Estratégias de marketing aplicadas à farmácia de oficina: estudo de um caso prático, Fernando Pessoa, 2010.

26. DEMETRESCO S. Tipologia e estética do visual merchandising. 2012. São Paulo: Estação das Letras e Cores.

27. FARDELONE LC, BRANCHI B.A. Mudanças Recentes no Mercado Farmacêutico, Revista da FAE, Curitiba, 2006, v. 9, n.1, p. 139-152, jun.

28. FERRAZ MB. Avaliação Econômica em Saúde. In: Neto, G. V., Malik, A. M. Gestão em Saúde. Rio de Janeiro: Guanabara Koogan, 2012.

29. GAVIOLI G, SIQUEIRA MCM, SILVA PHR. Aplicação do programa 5s em um sistema de gestão de Estoques de uma indústria de eletrodomésticos e seus Impactos na racionalização de recursos, Universidade Cruzeiro do Sul, 2009. 
30. GERLACH. G. Proposta de melhoria de layout visando a otimização do processo produtivo em um empresa de pequeno porte. Horizintina, 2013.

31. GONZALES, IVDP. Plano de Sucessão e Empresa Familiar: Estudo de Caso em uma Empresa de Mídia Exterior. Espirito Santo, 2012.

32. JUNIOR, CCMF. Aplicação da Ferramenta da Qualidade (Diagrama de Ishikawa) e do PDCA no Desenvolvimento de Pesquisa para a reutilização dos KELLER K, KOTLER P. Administração de Marketing. 2012.14. ed. São Paulo: Pearson Education do Brasil.

33. KOTLER P, ARMSTRONG G. Princípios de marketing. 2003, $9^{\circ}$ ed. São Paulo - Prentice Hall.

34. LOOF S. A. Administração farmacêutica simplificada. 2003, 3 ed. Porto Alegre.

35. MEDINA TL. O CONSUMIDOR E A LOJA: Uma investigação das estratégias de visual merchandising e Administração do Layout no ponto-de-venda, fundamentadas no comportamento do consumidor. 2015. Disponível em: http://www.labcom.fau.usp.br/wp-content/uploads/2015/05/3_cincci/039-tatiana-medina.pdf, acesso em 12/05/18, as 19:00hs.

36. MELLO B. Tendências mundiais do merchandising. Disponível em: <www. mundodomarketing.com.br $>$ Acessado em: 07 de março de 2016.

37. MENEZES JO, MONTEIRO S.; RODRIGUES S. Análise e redesenho do layout de uma empresa: Estudo de caso de uma fundição de alumínio, XIII SIMPEP, Bauru, SP, 2006.

38. MORGAN T. Visual Merchandising - Vitrines e Interiores Comerciais. São Paulo: G. Gilli, 2011.

39. NOYCE PR. Providing Patient Care Through Community Pharmacies in the UK: Policy, practice and research. Ann Pharcother, V. 41, n. 5, p. 861-867, 2007.

40. ORTIZ A. O uso de medidas de extensão e intensidade no intercâmbio de informações na cadeia de suprimentos do setor farmacêutico brasileiro. 2013. Dissertação (Mestre em Logística) - Departamento de Engenharia Indústria da Pontifícia, Universidade Católica do Rio de Janeiro, 2013.

41. PEREIRA PFP, BASTOS CF. Um estudo sobre a fidelização de clientes a partir de estratégias de marketing de relacionamento no segmento de farmácias e drogarias. Simpósio de Excelência em Gestão e Tecnologia, São Paulo, 2013.

42. RAMOS T. Fuja das Sombras. Rev. Guia de Farmácias, junho de 2014.

43. RODRIGUES ATL, LEMOS IS. Ferramentas de gestão para organizações Contábeis, Porto Alegre, v. 9, n. 16, 2 semestre 2009 .

44. SAAB WGL. Um panorama do varejo de farmácias e Drogarias, no Brasil, Rio Grande do Sul, 2001.

45. SANTOS AHN, ANTONELLI MM. Ferramentas de gestão financeira essencial para o sucesso de pequenas empresas: o caso Organização contábil santa ritaltdaepp. Faculdade cenecista de capivari. Capivari-SP, 2011.

46. SILVA RDVO, PINHEIRO VS. O Visual Merchandisingde Loja de Varejo de Moda, Congresso Brasileiro da Comunicação, Santa Catarina, 2010.

47. SOUSA MV, RICARTE MAC. A formulação das estratégias em farmácias e drogarias localizadas na mesorregião norte noroeste do estado do ceará, à luz das escolas de mintzberg. Xxxiii encontro nacional de engenharia de produção, Salvador, 2013.

48. SOUSA SDS. Farmacêuticos e suas atividades em farmácias comunitárias: uma análise de perfil. 2012. Monografia de Conclusão de Curso (Especialização em ciências Farmacêuticas) - Centro de ciências da Saúde, Universidade Federal do Rio Grande do Norte, 2012.

49. TELES CCS, BILENKY J, REIS VS et al. O Varejo aplicado ao mercado farmacêutico. Portal de periódicos eletrônicos - Fórum de administração - São Paulo, 2010, v. 2, n. 1:159-165. 